\title{
Management of Misnomer Pyogenic Granuloma in 7 Year Old Paediatric Patient - A Case Report
}

\section{Pallavi Yadavi*, Rakesh Kumar Chak ${ }^{2}$, Sandeep Pimpale ${ }^{3}$ and Geetika Prabhakar $^{3}$}

${ }^{1}$ Junior Resident-3, Department of Paediatric and Preventive Dentistry, KGMU,

Lucknow, India

${ }^{2}$ Professor, Department of Paediatric and Preventive Dentistry, FODS, King George's

Medical University, UP, Lucknow, India

${ }^{3}$ Department of Periodontics Nair Hospital Dental College, Mumbai, India

*Corresponding Author: Pallavi Yadav, Junior Resident-3, Department of Paediatric and Preventive Dentistry, KGMU, Lucknow, India.
Received: May 27, 2021

Published: June 23, 2021

(C) All rights are reserved by Pallavi Yadav and Rakesh Kumar Chak.

\begin{abstract}
Pyogenic Granuloma or lobular capillary haemangioma is a benign hyperplastic inflammatory which may bleed on probing. It most commonly seen in females and in second decade of life. Etiological factors include trauma, local irritation and others. Treatment of choice is complete excision along with removal of local factors. We present a case report of 7 year old paediatric patient involving the labial mucosa with respect to maxillary tooth region. Total excision was done with no recurrence rate on follow up of one year.
\end{abstract}

Keywords: Pyogenic Granuloma; Haemangioma; Epulis; Reactive; Hyperplastic

\section{Introduction}

In children, soft tissue growths are most common in oral cavity. To identify and treat them is of utmost importance as a paediatric dentist and also sometimes challenging due to their various differential diagnosis. Soft tissue growth leads to many differential diagnosis which falls into these categories; normal anatomical variations, cysts, developmental and lastly, neoplastic growths. Esmeili., et al. proposed that Reactive hyperplasia is one of the most common growths arising from chronic local tissue irritation due to extra stimulation of the tissue repair mechanism [1]. Pyogenic granuloma is one of the reactive hyperplasia soft tissue growths but, Aetiology is unknown. However, many different theories have been proposed regarding the etiopathogenesis of pyogenic granuloma. It is a misnomer because it does not contain pus and also do not exhibit features of granuloma histologically [2]. It most commonly involve gingiva. Extra gingivally, it involves lip, tongue, palate, buccal mucosa [3]. It's first case reported by Poncet and Dorr in 1897 and was called Botryomycosis hominis [3]. Pyogenic granuloma have been given several names like granuloma pedicu- latum benignum, benign vascular tumour, pregnancy tumour, vascular epulis. It is also called as "Crocker and Hartzell's disease" and "pyogenic granuloma" termed by crocker in 1903 [4]. Angelopoulos AP called it as a "Haemangiomatous granuloma" [5]. Cawson., et al. suggested that it contains numerous blood vessels, so termed as "granuloma telangiectasia" [6]. Bhaskar., et al. in his study revealed that it comprises of $1.85 \%$ of all the pathoses [7]. Daley., et al. revealed that pregnancy epulides comprises only 42 out of 727 epulides of all types [8]. In a study by Shamim., et al. 244 cases of gingival lesions in south Indian population, found that nonneoplastic lesions accounted for $75.5 \%$ of cases with oral pyogenic granuloma accounting for $52.71 \%$ cases being the most frequent lesion [9].

\section{Case Report}

A 7 year old male child reported to the outpatient department with the chief complaint of soft, painless nodular growth on labial mucosa in the upper right premolar region which bleeds at any time (not specific). The Patient was asymptomatic 5 days back and then he noticed a globular round painless growth on the right side labial mucosa which sometimes bleeds while brushing so he 
stopped brushing in the associated region. On taking history there was no history of trauma. His medical and family histories were non contributary. His general physical examination revealed no other abnormalities. There were no relevant abnormal extraoral findings, and there were no palpable regional lymph nodes. The intraoral examination revealed moderately satisfactory oral hygiene and hence, no cavitation and other abnormalities in teeth. On soft tissue examination growth was round, painless globular growth. The growth was light pink, brownish, white in color around $1.5 \mathrm{x}$ $1.3 \times 0.4 \mathrm{~cm}$ in size. The surface of growth was irregular and firm in consistency. The growth was non tender and firm on palpation and on probing; there was severe bleeding from the lesion. A provisional diagnosis of traumatic fibroma was given. Differential diagnosis of irritational fibroma, pyogenic granuloma was given.

Patient was advised to get the haematological and biochemical investigations done. The investigation reports were within limits.

An excisional biopsy was planned and the excised tissue was sent for histopathological examination. The biopsy report revealed overlying para keratinized stratified squamous epithelium with underlying connective tissue stroma. Numerous blood vessels of varying size are seen in moderately dense and fibro cellular connective tissue stroma. These blood vessels are lined by plump endothelial cells with extravasated RBC's. plump fibroblasts with moderate chronic inflammatory cell infiltrated chiefly composed of lymphocytes are also seen. Histologically, pyogenic granuloma was confirmed diagnosis. Patient was recalled for follow up after one week for the suture removal and then, at weekly intervals follow up until 3 months. No recurrence was seen in further follow up period.

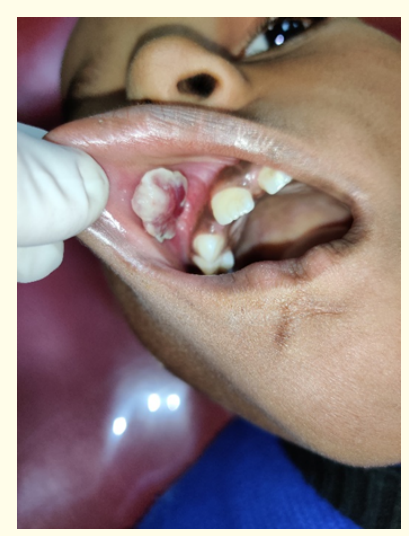

Figure 1: Intraoral.

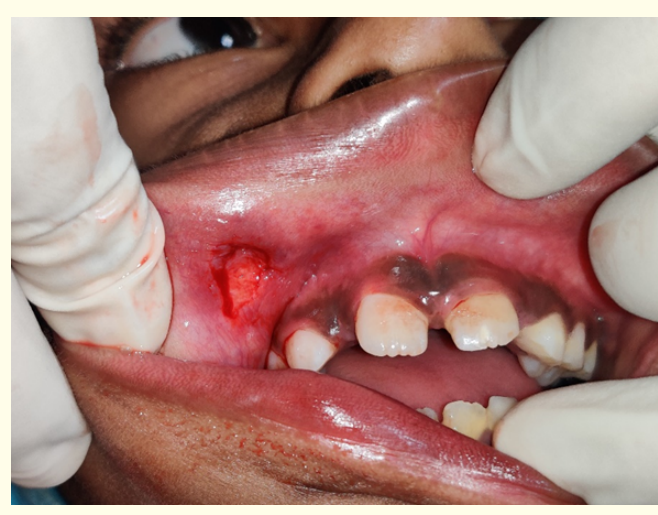

Figure 2: Surgical excision done.

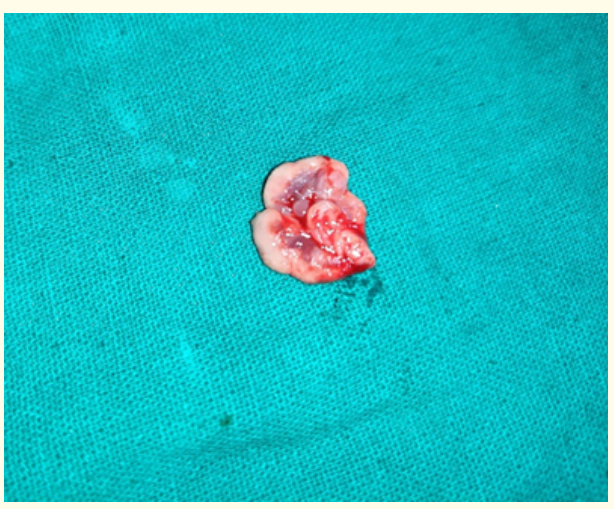

Figure 3: Specimen.

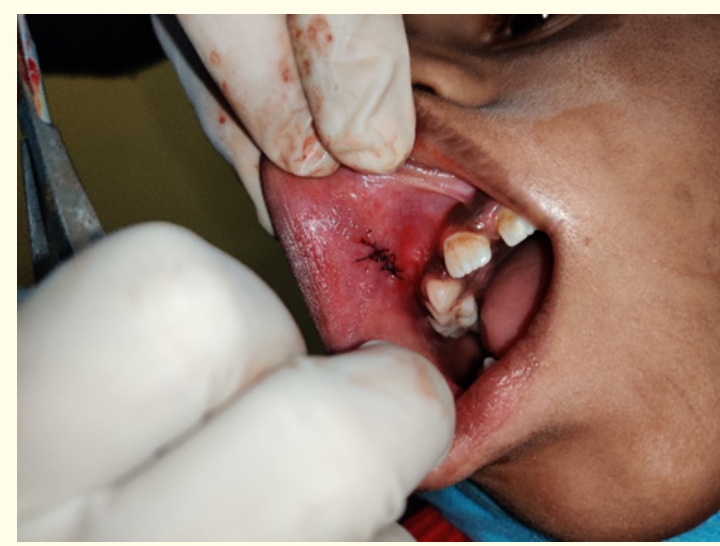

Figure 4: Sutures placed. 


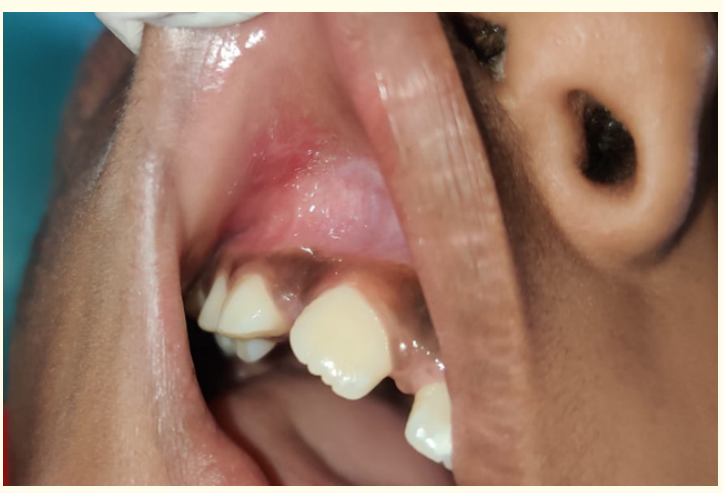

Figure 5: 1 month follow up.

\section{Discussion and Conclusion}

According to few researchers "Pyogenic granuloma"' term given by Hartzell [5]. It is a hyperplastic inflammatory lesion and also known as granuloma pyogenicum [10]. Histologically it is referred by different names like haemangiomatous granuloma by Angelopoulos due to increase in blood vessels [5], granuloma telangiectacticum by Cawson., et al. [6] it is also known as Crocker and Hartzell's disease [4]. There are two main types - lobular capillary haemangioma and Non lobular capillary haemangioma [10].

Aetiology is unknown but related to several factors like calculus or foreign material within the gingival crevice by Regezi., et al. [12], repeated trauma due to frequent tooth brushing by Ainamo [13]. Trauma to deciduous teeth [14], aberrant tooth development [15], occlusal interferences [16], immunosuppressive drugs such as cyclosporine [17] and wrong selection of healing cap for implants [18] are some of the other precipitating factors for pyogenic granulomas. However, Supriya Sharma., et al. [31] depicted etiology to be of heterogenous nature.

Oral pyogenic granuloma most commonly occur in female during second decades due to increased levels of hormones [19]. It appears as an elevated, erythematous, haemorrhagic, papules with sessile or pedunculated base which can show ulcerations and can be covered by a fibrinous membrane $[12,20]$.

The colour varies from red, pink, purple, depending on the vascularity of the growth [21]. Gingiva is affected primarily, especially the marginal gingiva and common in maxillary than man- dibular gingiva. Labial vermillion border is found to be one most neglected sites by the dentists. Assim Banjar., et al. [30] in his article advised dentists to involve labial pyogenic granuloma in the differential diagnosis of lower lip and upper lip lesions Anterior areas are most commonly affected than posterior areas and more common on the facial than the lingual aspect [20]. Radiographic findings are usually absent [3] but few longstanding cases, bone resorption is noticed [5]. Differential diagnosis of pyogenic granuloma involve hyperplastic gingival inflammation, peripheral giant cell granuloma, peripheral ossifying fibroma, metastatic cancer, haemangioma, pregnancy tumour, non-Hodgkin s Lymphoma. Kaposiss sarcoma, bacillary angiomatosis, angiosarcoma [22]. Fibroma can be distinguished from pyogenic granuloma from its consistency, colour and texture [20]. Peripheral giant cell granuloma looks similar to giant cell granuloma but bone resorption and appearance of multinucleated giant cells are the differentiating features [12], metastatic cancer resembles pyogenic granuloma but we can differentiate it by its tumour like microscopic appearance [20]. Haemangioma can be differentiated as it is a developmental anomaly commonly seen on tongue and can be distinguished by chair side test called diascopy [23]. Bacillary angiomatosis and Kaposi sarcoma can be differentiated histopathologically and also aids related [10]. Pregnancy tumour occurrence rate is higher by the end of pregnancy and shrinkage of the lesion after delivery marks its differentiating characteristic [24]. Angiosarcoma by its lobular growth pattern, well-formed vessels and cytologically bland of endothelial cells [10].

Histologically, pyogenic granuloma has two types - LCH and non-LCH. In LCH [20], blood vessels in lobular aggregates seen and non LCH consist of vascular core resembling granulation tissue with foci of fibrous tissue. Lobular lesion has greater number of vessels and oral pyogenic granuloma are mainly LCH type [11].

Treatment modalities of pyogenic granuloma includes excisional biopsy with removal of local irritants for small painless lesions. And for larger extent of lesions, excision of gingival lesions up to periosteum with thorough scaling and root planning of adjacent teeth to remove all visible irritants [20]. Various other treatment modalities include carbon dioxide lasers, $\mathrm{Nd}$ : Yttrium-aluminumgarnet lasers, pulse dye laser, flash lamp, cryosurgery, sodium tetradecyl sulphate sclerotherapy [10] and use of intralesional steroids have been proposed by different clinicians. However, the 
systemic review study done by Mohammed dany [32] has proposed the use of oral and topical Beta blockers such as timolol, propranolol, and betaxolol for the treatment of pyogenic granuloma. In future treatments study done by Ali Dehghani Nazhvani., et al. [33] there is a scope of extracting stem cells from the lesion as the cells from the lesion found to be of differentiating potential. In pregnancy tumour treatment includes preventive measures such as proper oral hygiene, removal of dental plaque and use of a soft toothbrush [25]. Wang advised in case of uncontrolled bleeding from pregnancy tumour the treatment includes control of bleeding by desiccation of bleeders, firm compression, blood transfusions in a case of severe bleeding and in rare cases termination of pregnancy due to uncontrollable eclampsia have also been documented [26]. In cases of shrinkage of lesion after lesion, surgical treatment will be unnecessary [2]. In pregnant females, recurrence rates are higher so advised treatment after parturition [27]. Taira., et al. report have shown a recurrence rate of $16 \%$ in excised lesions and described the reason of recurrence as multiple deep satellite lesions surrounding the original excised lesion [28]. Other reasons for recurrence rates can be Incomplete excision, failure to remove or repeated trauma [12]. Vilmann., et al. pointed the need for follow up as it has high recurrence rates [29].

\section{Financial Support and Sponsorship}

Nil.

\section{Conflict of Interest}

No conflict of interest.

\section{Bibliography}

1. Esmeili T., et al. "Common benign oral soft tissue masses". Dental Clinics of North America 49 (2005): 223-240.

2. Bouquot JE and Nikai H. "Lesions of oral cavity". In: Gnepp DR, editor. Diagnostic Surgical Pathology of Head and Neck. Philadelphia: W B Sanders (2001): 141-233.

3. Kamal R., et al. "Oral pyogenic granuloma: Various concepts of etiopathogenesis". Journal of Oral and Maxillofacial Pathology: JOMFP 16.1 (2012): 79.

4. Hartzell MB. "Granuloma pyogenicum". Journal of Oral and Maxillofacial Surgery 22 (1904): 520-525.
5. Angelopoulos AP. "Pyogenic granuloma of the oral cavity: Statistical analysis of its clinical features". Journal of Oral and Maxillofacial Surgery 29 (1971): 840-847.

6. Cawson RA., et al. "Lucas Pathology of Tumors of Oral Tissues". 5th edition. Missouri: Mosby (1998): 252-254.

7. Bhaskar SN and Jacoway JR. "Pyogenic granuloma - clinical features, incidence, histology, and result of treatment: Report of 242 cases". Journal of Oral and Maxillofacial Surgery 24 (1966): 391-398.

8. Daley TD., et al. "Pregnancy tumor: An analysis". Oral Surgery, Oral Medicine, Oral Pathology, and Oral Radiology 72 (1991): 196-199.

9. Shamim T., et al. "A retrospective analysis of gingival biopsied lesions in south Indian population: 2001-2006". Medicina Oral, Patologia Oral, Cirugia Bucal 13 (2008): 414-418.

10. Jafarzadeh H., et al. "Oral pyogenic granuloma: A review”. Journal of Oral Science 4 (2006): 167-175.

11. Gomes SR., et al. "Pyogenic granuloma of the gingiva: A misnomer? - A case report and review of literature". Journal of Indian Society of Periodontology 17 (2013): 514-519.

12. Regezi JA., et al. "Oral pathology and clinical pathological considerations". $4^{\text {th }}$ edition. Philadelphia: W B Saunders (2003): 115-116.

13. Ainamo J. "The effect of habitual tooth cleansing on the occurrence of periodontal disease and dental caries". Suomen Hammaslaakariseuran Toimituksia 67 (1971): 63-70.

14. Aguilo L. "Pyogenic granuloma subsequent to injury of a primary tooth. A case report". International Journal of Paediatric Dentistry 12 (2002): 438-441.

15. Milano M., et al. "Pyogenic granuloma associated with aberrant tooth development". The Texas Dental Journal 118 (2001): 166-172.

16. Widowati W., et al. "Epulis and pyogenic granuloma with occlusal interference". Majalah Kedokteran Gigi 38 (2005): 5255.

17. Bachmeyer C., et al. "Pyogenic granuloma of the tongue in chronic graft versus host disease". Annales de Dermatologie et de Vénéréologie 123 (1996): 552-554. 
18. Dojcinovic I., et al. "Occurrence of a pyogenic granuloma in relation to a dental implant". Journal of Oral and Maxillofacial Surgery 68 (2010): 1874-1876.

19. Ojanotko-Harri AO., et al. "Altered tissue metabolism of progesterone in pregnancy gingivitis and granuloma". Journal of Clinical Periodontology 18 (1991): 262-266.

20. Neville BW., et al. "Oral and Maxillofacial Pathology". $2^{\text {nd }}$ edition. Philadelphia: Saunders (2002): 437-495.

21. Mubeen K., et al. "Oral pyogenic granuloma with mandible involvement. An unusual presentation". Journal of Dentistry and Oral Hygiene 3 (2011): 6-9.

22. Calonje E and Wilson Jones E. "Vascular tumours: Tumours and tumour like conditions of blood, vessels and lymphatics". In: Elder D, Elenitsas R, Jaworsky C, Johnson BJ, editors. Lever's Histopathology of the Skin. 8 th edition. Philadelphia: Lippincott-Raven (1997): 895.

23. Greenberg MS and Glick M. "Burket's Oral Medicine”. Diagnosis and Treatment. $11^{\text {th }}$ edition. McGraw Hill (2003): 130.

24. Sonis ST., et al. "Principles and Practice of Oral Medicine". $2^{\text {nd }}$ edition. Philadelphia: W B Saunders (1995): 416.

25. Steelman R and Holmes D. "Pregnancy tumor in a 16-year-old: Case report and treatment considerations". The Journal of Clinical Pediatric Dentistry 16 (1992): 217-218.

26. Wang PH., et al. "Severe bleeding from a pregnancy tumor. A case report". The Journal of Reproductive Medicine 42 (1997): 359-362.

27. Eversole LR. "Clinical Outline of Oral Pathology: Diagnosis and Treatment. $3^{\text {rd }}$ edition. Hamilton: BC Decker; (2002): 113-114.

28. Taira JW., et al. "Lobular capillary hemangioma (pyogenic granuloma) with satellitosis". Journal of the American Academy of Dermatology 27.2-2 (1992): 297-300.

29. Vilmann P and Vilmann H. "Pyogenic granuloma: Evaluation of oral conditions". British Journal of Oral and Maxillofacial Surgery 24 (1986): 376-382.

30. Banjar A., et al. "Labial pyogenic granuloma related to trauma: A case report and mini-review". Dental Traumatology 36.4 (2020): 446-451.

31. Sharma S., et al. "Heterogeneous conceptualization of etiopathogenesis: Oral pyogenic granuloma”. National Journal of Maxillofacial Surgery 10.1 (2019): 3-7.
32. Dany M. "Beta-Blockers for Pyogenic Granuloma: A Systematic Review of Case Reports, Case Series, and Clinical Trials". Journal of Drugs in Dermatology 18.10 (2019): 1006-1010.

33. Dehghani Nazhvani A., et al. "Purification of Stem Cells from Oral Pyogenic Granuloma Tissue". The Open Dentistry Journal 29 (2018): 12.

\section{Volume 4 Issue 7 July 2021}

(C) All rights are reserved by Pallavi Yadav., et al. 